1 Private practice, Chapecó, SC, Brazil.

${ }^{2}$ School of Dentistry, Community University of Chapecó Region (Unochapecó), Chapecó, SC, Brazil.

${ }^{3}$ Health Sciences Post-Graduate Program, Community University of Chapecó Region (Unochapecó), Chapecó, SC, Brazil.
Corresponding author:

Prof. Dr. Sinval Adalberto Rodrigues-Junior

Community University of Chapecó Region (Unochapecó), Health

Sciences Area

Servidão Anjo da Guarda 295-D

- Efapi, Zip code 89809-000,

Chapecó, SC, Brazil

Phone number: +55 (49) 3321-8069

e-mail: rodriguesjunior.sa@

unochapeco.edu.br

Received: September 23, 2019

Accepted: March 28, 2020

\section{In vitro tooth whitening effectiveness of whitening mouth rinses}

\author{
Ana Paula Morona Rodrigues ${ }^{1}$, Mariele Cristina \\ Klein', Mauro Antonio Dall Agnol ${ }^{2}$, Sinval Adalberto \\ Rodrigues-Junior ${ }^{3, *}$
}

Regardless of the extensive availability of mouth rinses that claim to whiten teeth, evidence of achievement of such effect is still missing. Aim: Therefore, this study assessed in vitro the whitening effectiveness of whitening mouth rinses. Methods: Sixty intact bovine incisors were embedded in acrylic resin and had their buccal surface flattened and polished. Then, the specimens were randomly allocated to three conventional (Colgate Plax, Cepacol and Listerine Cool Mint) and three whitening mouth rinse groups (Colgate Luminous White, Cepacol Whitening and Listerine Whitening Extreme) $(n=10)$. Following, the specimens were immersed twice a day in the mouth rinses for one minute for 28 days. In between each immersion period, the specimens remained in artificial saliva at $37^{\circ} \mathrm{C}$. Color was measured at baseline, $7,14,21$, and 28 days using a portable spectrophotometer (Easyshade, Vita Zahnfabrik, Germany) with a $6 \mathrm{~mm}$ of diameter probe. Color change was analyzed considering the parameters of $\Delta \mathrm{L}^{*}, \Delta \mathrm{a}^{*}, \Delta \mathrm{b}^{*}$ and, ultimately, $\Delta \mathrm{E}^{*}$. The whitening efficacy of the mouth rinses was analyzed using the Whiteness Index for Dentistry $\left(W I_{D}\right)$. Data of $\Delta s$ was analyzed using two-way ANOVA and Tukey's test ( $a=0.05)$. Results: The type of mouth rinse affected significantly all the $\Delta$ parameters $(p<0.05)$. A non-whitening (conventional) mouth rinse produced the highest $\Delta E^{*}$, followed by the three whitening mouth rinses. The application time also affected $\Delta E^{\star}(p<0.05)$, with emphasis on the third week of treatment. Only the hydrogen peroxide-containing mouth rinse (Listerine Whitening Extreme) presented a whitening effect, with an increasing trend over time. Conclusion: Although the overall color change was not different when comparing conventional and whitening mouth rinses, the hydrogen peroxide-containing whitening mouth rinse produces an increasing whitening trend over time. Not every mouth rinse that claims to whiten teeth produces the desired effect.

Keywords: Color. Mouthwashes. Nonprescription drugs. Tooth bleaching. Tooth bleaching agents. 


\section{Introduction}

Over-the-counter (OTC) whitening products have been available in the dental market since the 2000s, increasing the number of alternatives to meet the tooth whitening demand. Different from in-office tooth whitening and tray-based home whitening, professional prescription and orientation are not mandatory for applying OTC products $^{1}$. Dentifrices, mouth rinses, whitening strips, dental flosses, and paint-on gels fall into the category of OTC whitening products and eventually contain low concentrations of hydrogen peroxide ${ }^{1,2}$.

Chemically-induced tooth whitening derives from the interaction of the whitening agent, which is usually hydrogen peroxide, with the dental structure. When applied, hydrogen peroxide diffuses into the dental structure and releases reactive oxygen molecules that, through oxidation, break the double bonds of organic and inorganic coloring molecules ${ }^{3}$. This process relies on both the concentration of the whitening agent and the contact time with the tooth ${ }^{4}$. We may apply hydrogen peroxide directly to the tooth or it may result from a chemical reaction from sodium perborate or carbamide peroxide. The concentration of the former presentation may vary from $5 \%$ to $35 \%$, and the latter, from $10 \%$ to $35 \%^{3}$, but a $10 \%$ carbamide peroxide solution produces only $3.35 \%$ hydrogen peroxide ${ }^{5}$.

Whitening mouth rinses may contain sodium hexametaphosphate, which protects the tooth surface from pigments ${ }^{2}$. They may also contain hydrogen peroxide at low concentrations, usually around $1.5 \%$ to $2 \%$, Nonetheless, this concentration is close to the hydrogen peroxide concentration of the ADA-recommended at-home whitening technique based on $10 \%$ carbamide peroxide gel ${ }^{3}$, suggesting a whitening potential for this oral hygiene technology. However, the contact time of mouth rinses with the tooth surface is low, lasting for only a few minutes and leading to questioning about the whitening capacity of these products under the application circunstances

While a long-term randomized controlled trial ${ }^{7}$ confirmed the whitening efficacy and safety of professionally supervised tooth whitening procedures, studies attesting the efficacy of whitening mouth rinses are scarce. From the best of our knowledge, there are no clinical trials attempting to verify the whitening efficacy and the possible production of adverse effects by whitening mouth rinses. Also, the few existing in vitro studies that compare whitening mouth rinses between themselves and with other whitening alternatives vary a lot methodologically. Based on that, discrepancies related to the whitening potential, either in favor of the whitening mouth rinses $s^{6,8,9}$ or towards no difference ${ }^{10}$ may have been caused by different methodological decisions.

This scenario impairs comparisons between products and a sound decision-making process by either consumers or dental professionals responsible for indicating tooth whitening and oral hygiene products. Therefore, the present study aimed to inform about the in vitro whitening efficacy of whitening mouth rinses, testing the hypothesis that there is no difference in color change results from the type of mouth rinse. 


\section{Materials and Methods}

\section{Specimen preparation}

For this in vitro study, 60 extracted intact bovine incisors were stored in $0.1 \%$ thymol solution for seven days and cleaned with pumice and Robinson brush using a low-speed handpiece (KaVo, Joinville, SC, Brazil). Next, the roots were removed using a high-speed cutting saw (Figure 1-A) and the teeth were embedded in chemically cured acrylic resin (VipiFlash, Vipi, Pirassununga, SP, Brazil) (Figure 1-B). Then, the buccal surfaces of the specimens were ground and polished using \#400,600, and 1200 grit sandpapers under water cooling, leaving a flat surface area of at least $6 \mathrm{~mm}^{2}$ in the center and cervical regions of the tooth (Figure 1-C). Teeth that had their enamel removed during grinding and polishing were excluded. The included specimens were stored in artificial saliva prior to the experiment.

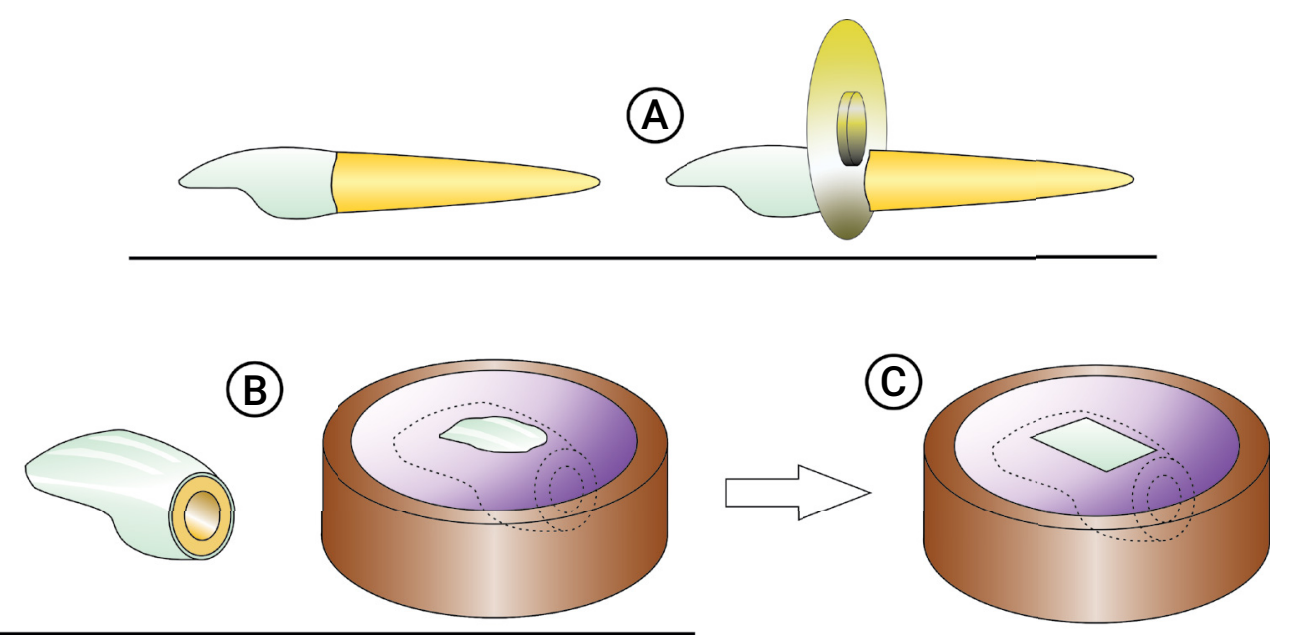

Figure 1. Specimen preparation: A - root removal; B - tooth embedding in chemically cured acrylic resin; $\mathrm{C}$ - grinding and polishing of the specimen's buccal surface

\section{Immersion protocol}

An online random sequence generator (www.random.org) randomized the specimens to any of the six mouth rinse groups $(n=10)$ (Table 1$)$. Considering that most manufacturers recommend a one-minute mouthwash, the specimens were immersed in the mouth rinses for one minute, twice a day. The trial period lasted for 28 days. After immersion, the mouth rinses were discarded, and the specimens were returned to the artificial saliva and maintained at $37^{\circ} \mathrm{C}$. The artificial saliva was replaced daily.

\section{Color assessment}

A single operator measured color with the help of an Easyshade portable spectrophotometer (Vita Zahnfabrik, Bad Säckingen, Germany), at baseline and after 7, 
Table 1. Substances used in the study

\begin{tabular}{|c|c|c|}
\hline Product & Manufacturer & Components \\
\hline $\begin{array}{l}\text { Artificial saliva } \\
\left.\text { (Santos }{ }^{11} 2008\right)\end{array}$ & $\begin{array}{l}\text { Unochapecó Pharmacology } \\
\text { Laboratory }\end{array}$ & $\begin{array}{l}\text { Potassium chloride, sodium chloride, magnesium chloride, } \\
\text { potassium phosphate, calcium chloride, nipagin, nipasol, } \\
\text { carboxymethylcellulose, sorbitol, distilled water }\end{array}$ \\
\hline Colgate Plax & $\begin{array}{l}\text { Colgate-Palmolive, São } \\
\text { Bernardo do Campo, SP, } \\
\text { Brazil }\end{array}$ & $\begin{array}{l}\text { Water, glycerin, propylene glycol, sorbitol, poloxamer } 338 \text {, } \\
\text { poloxamer } 407 \text {, aroma, PEG- } 40 \text { hydrogenated castor oil, } \\
\text { cetylpyridinium chloride, potassium sorbate, sodium } \\
\text { fluoride, sodium saccharin, citric acid, sucralose, Cl } 42053\end{array}$ \\
\hline Cepacol & $\begin{array}{l}\text { Sanofi-Aventis } \\
\text { Farmacêutica Ltda., Suzano, } \\
\text { SP, Brazil }\end{array}$ & $\begin{array}{c}\text { Alcohol, water, cetylpyridinium chloride, disodium EDTA, } \\
\text { sodium saccharin, polysorbate } 80 \text {, glycerin, sodium } \\
\text { phosphate, disodium phosphate, eucalyptol, menthol, } \\
\text { methyl salicylate, aroma, parfum (benzyl alcohol, } \\
\text { cinnamal), Cl } 19140\end{array}$ \\
\hline $\begin{array}{l}\text { Listerine Cool } \\
\text { Mint }\end{array}$ & $\begin{array}{l}\text { Johnson \& Johnson } \\
\text { Industrial Ltda., Yumbo, } \\
\text { Valle, Colombia }\end{array}$ & $\begin{array}{l}\text { Water, sorbitol, alcohol, poloxamer } 407 \text {, benzoic acid, } \\
\text { sodium saccharin, eucalyptol, aroma (d-limonene), thymol, } \\
\text { methyl salicylate, sodium benzoate, menthol, } \mathrm{Cl} 42053\end{array}$ \\
\hline $\begin{array}{l}\text { Colgate } \\
\text { Luminous White }\end{array}$ & $\begin{array}{l}\text { Colgate-Palmolive, São } \\
\text { Bernardo do Campo, SP, } \\
\text { Brazil }\end{array}$ & $\begin{array}{l}\text { Water, glycerin, propylene glycol, sorbitol, tetrapotassium } \\
\text { pyrophosphate, polysorbate } 20 \text {, tetrasodium } \\
\text { pyrophosphate, zinc citrate, PVM/MA copolymer, } \\
\text { aroma, benzyl alcohol, sodium fluoride, sodium saccharin, } \\
\text { Cl } 42051\end{array}$ \\
\hline $\begin{array}{l}\text { Cepacol } \\
\text { Whitening }\end{array}$ & $\begin{array}{l}\text { Sanofi-Aventis } \\
\text { Farmacêutica Ltda., Suzano, } \\
\text { SP, Brazil }\end{array}$ & $\begin{array}{l}\text { Water, sorbitol, glycerin, sodium benzoate, sodium } \\
\text { saccharin, sodium cyclamate, poloxamer 407, PEG-40 } \\
\text { hydrogenated castor oil, PVP, methylparaben, aroma } \\
\text { (eugenol, d-limonene and linalool), citric acid, propylene } \\
\text { glycol, cetylpyridinium chloride and sodium fluoride }\end{array}$ \\
\hline $\begin{array}{l}\text { Listerine } \\
\text { Whitening } \\
\text { Extreme }\end{array}$ & $\begin{array}{l}\text { Johnson \& Johnson } \\
\text { Industrial Ltda., Yumbo, } \\
\text { Valle, Colombia }\end{array}$ & $\begin{array}{l}\text { Water, alcohol, } 2.5 \% \text { hydrogen peroxide, aroma, poloxamer } \\
407, \text { sodium saccharin, menthol, phosphoric acid, } \\
\text { disodium phosphate, sodium fluoride, sucralose }\end{array}$ \\
\hline
\end{tabular}

14,21 , and 28 days of immersion. Color was read after a minimum interval of two hours after the last immersion in the mouth rinses, by positioning the $6-\mathrm{mm}$ tip of the spectrophotometer between the middle and cervical thirds of the specimen, perpendicular to the specimen's flat surface. A standard white background was used for all measurements, under the same lightning. Color expression was based on the three-dimensional color space of the CIEL*a*b* system consisting of three distinct axes. The $L^{*}$ axis varies from 0 to 100 and represents the degree of lightness in color, considering 0 totally black and 100 totally white; $a^{*}$ represents the variation between green (a-) and red (a+); and $b^{*}$ represents the variation between blue (b-) and yellow (b+). The $L^{\star}, a^{\star}$, and $b^{\star}$ values in each assessment interval allowed determining a $\Delta$ for each parameter and ultimately calculating $\Delta \mathrm{E}^{\star}$, which is a non-directional summary of color change based on the $\Delta s$ of each directional parameter, as follows:

$$
\Delta E^{\star}{ }_{a b}=\sqrt{\left(L_{2}^{\star}-L_{1}^{\star}\right)^{2}+\left(a_{2}^{\star}-a_{1}^{\star}\right)^{2}+\left(b_{2}^{\star}-b_{1}^{\star}\right)^{2}}
$$

\section{Analysis of whitening efficacy}

The whitening efficacy of the mouth rinses was assessed using the Whitening Index for Dentistry $\left(\mathrm{WI}_{\mathrm{D}}\right)^{12}$, which is calculated as follows: 


$$
W I_{D}=0.511 L^{\star}-2.324 a^{\star}-1.100 b^{\star}
$$

According to the authors ${ }^{12}$, high positive values of the index indicate high whiteness in the specimen; low values, and even negative values indicate low values of whiteness.

\section{Data analysis}

For statistical data analysis of the $\Delta s$, the adherence of data to the normal distribution was verified using the Anderson-Darling test. Levene's test was used to check for equal variances and Grubb's test for the presence of outliers. When identified, outliers were removed from the dataset. Two-way ANOVA and Tukey's test verified the influence of time and the type of mouthwash on color and color change $(\triangle)$, at a $5 \%$ significance level (Minitab 17.0, Minitab LLC, State College, PA, USA). Data of WI were analyzed descriptively considering each mouth rinse and the application time period, based on the parameters set by Perez et al. ${ }^{12}$ (2016).

\section{Results}

Figure 2 shows the changes in $L^{*}, a^{*}$, and $b^{*}$ by immersion in the mouth rinses.

Table 2 presents the results of $\Delta \mathrm{L}^{*}, \Delta \mathrm{a}^{*}, \Delta \mathrm{b}^{*}$, and $\Delta \mathrm{E}^{*}$. The mouth rinse affected $\Delta L^{*}$ significantly $(p=0.017)$, while time $(p=0.107)$ and the mouth rinse $x$ time interaction $(p=0.971)$ were not significant. Listerine Whitening Extreme produced the lowest reduction in L* (-3.60), while Listerine Cool Mint and Cepacol Whitening generated the greatest reduction (-10.29 and -9.91 , respectively). Similarly, the mouth rinse significantly affected $\Delta b^{*}(p<0.0001)$, while time $(p=0.844)$ and the mouth rinse $x$ time interaction $(p=0.229)$ were not significant. Listerine Whitening Extreme produced the greatest reduction in $b^{*}$ values $(-5.78)$, followed by Colgate Luminous White (-2.94). The mouth rinse affected $\Delta a^{\star}$ significantly $(p=0.02)$, which did not occur for either time $(p=0.142)$ or the mouth rinse $x$ time interaction $(p=0.791)$. Listerine Whitening Extreme provided the greatest reduction in $a^{*}$ values $(-0.88)$, while Cepacol Whitening increased $a^{\star}(0.91)$. Mouth rinse $(p<0.0001)$ and time $(p=0.002)$ affected $\Delta E^{\star}$ significantly, which did not occur for their interaction $(p=0.739)$. Listerine Cool Mint produced the highest $\Delta E^{\star}$ (13.72), while Cepacol showed the lowest $\Delta E^{\star}$ (7.99). The three whitening mouth rinses produced intermediate $\Delta E^{*}$ values. The period of 21 days of mouth rinse application resulted in the highest $\Delta E^{\star}(14.26)$.

As to $\mathrm{WI}_{\mathrm{D}}$ results, all groups presented negative mean values, except Listerine Whitening Extreme. Also, the index values per application time were always negative in all groups. Again, the exception was the hydrogen peroxide-containing Listerine Whitening Extreme, which raised the index values from baseline and became positive only after 14 days-application time (Figure 3). The mean, minimum and maximum $\mathrm{WI}_{\mathrm{D}}$ values of the groups are as follows: Cepacol (Mean=-10.9; minimum=-28.5; maximum=5.31); Cepacol Whitening (Mean=-15.4; minimum=-27.6; maximum=0.03); Colgate Plax (Mean=-8.3; minimum=-23.6; maximum=8.9); Colgate Luminous White (Mean=-10.7; minimum=-25.1; maximum=5.2); Listerine Cool Mint (Mean=-13.4; minimum=-33.4; maximum=8.4); Listerine Whitening Extreme (Mean=0.11; minimum=-21.5; maximum=25.8). 


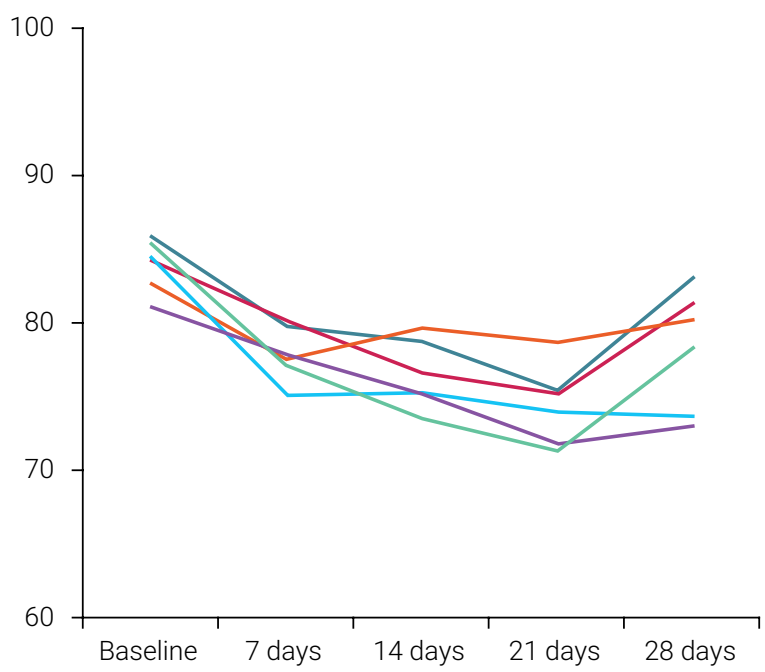

A
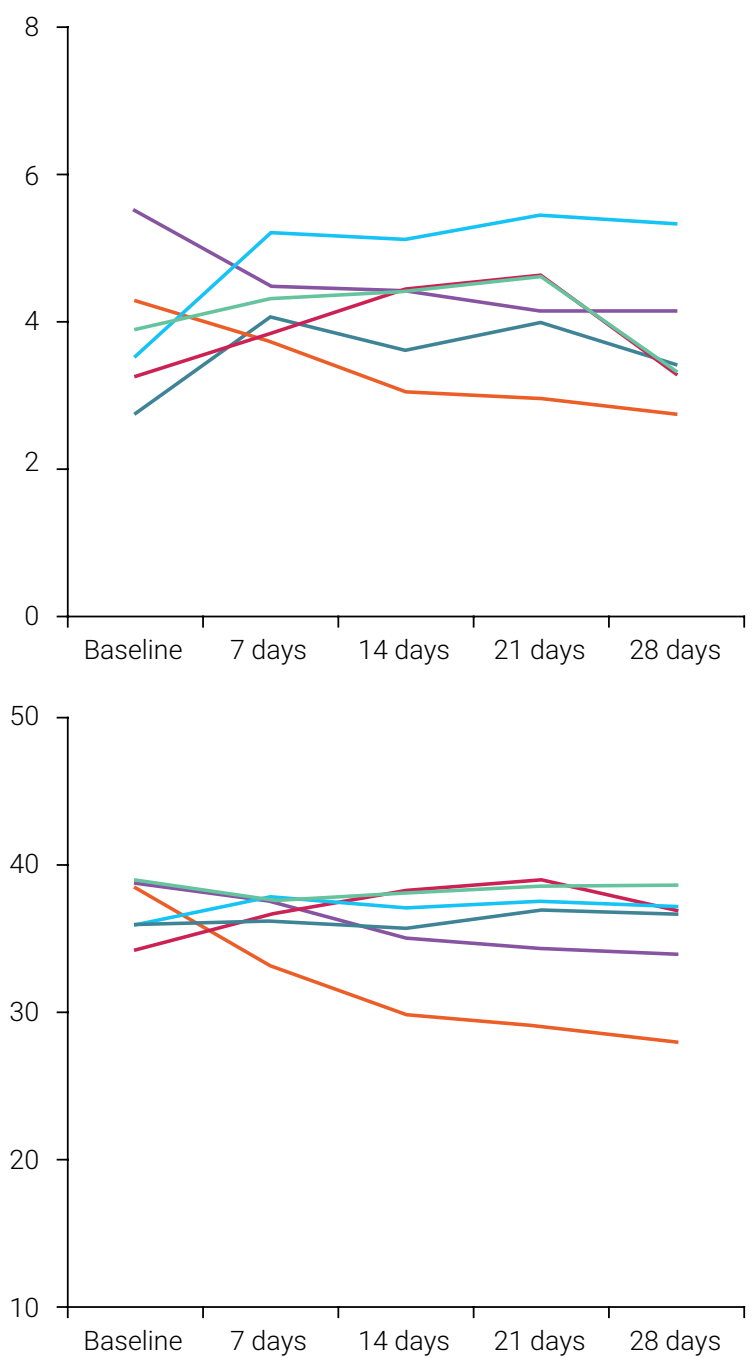

C

- Colgate Plax

- Cepacol

_ Listerine Cool Mint

_ Colgate Luminous White

_ Cepacol Whitening

_ Listerine Whitening Extreme

Figure 2. Behavior of $L^{*}(A), a^{*}(B)$ and $b^{*}(C)$ parameters, respectively, throughout the experiment 
Table 2. Results of $\Delta \mathrm{L}^{*}, \Delta \mathrm{a}^{*}, \Delta \mathrm{b}^{*}$ and $\Delta \mathrm{E}^{*}$ (mean and SD) for each assessment interval

\begin{tabular}{|c|c|c|c|c|c|c|c|}
\hline & Time & Colgate Plax & Cepacol & $\begin{array}{l}\text { Listerine Cool } \\
\text { Mint }\end{array}$ & $\begin{array}{l}\text { Colgate } \\
\text { Luminous } \\
\text { White }\end{array}$ & $\begin{array}{l}\text { Cepacol } \\
\text { Whitening }\end{array}$ & $\begin{array}{l}\text { Listerine } \\
\text { Whitening } \\
\text { Extreme }\end{array}$ \\
\hline \multirow[t]{4}{*}{$\Delta \mathrm{L}^{*}$} & B-7 & $-6.11(5.68)^{a}$ & $-4.12(6.40)^{\mathrm{a}}$ & $-8.26(6.99)^{a}$ & $-3.21(14.14)^{\mathrm{a}}$ & $-9.30(7.33)^{\mathrm{a}}$ & $-5.10(9.16)^{a}$ \\
\hline & B-14 & $-7.14(9.69)^{a}$ & $-7.65(5.43)^{\mathrm{a}}$ & $-11.83(12.38)^{a}$ & $-5.90(11.78)^{\mathrm{a}}$ & $-9.17(9.51)^{\mathrm{a}}$ & $-3.00(10.41)^{a}$ \\
\hline & B-21 & $-10.45(8.58)^{a}$ & $-9.06(5.47)^{\mathrm{a}}$ & $-14.05(13.62)^{\mathrm{a}}$ & $-9.27(9.99)^{\mathrm{a}}$ & $-10.45(8.14)^{a}$ & $-3.92(10.63)^{a}$ \\
\hline & B-28 & $-2.78(7.84)^{a}$ & $-2.93(4.30)^{\mathrm{a}}$ & $-7.02(9.25)^{\mathrm{a}}$ & $-8.07(14.47)^{\mathrm{a}}$ & $-10.71(7.57)^{\mathrm{a}}$ & $-2.39(9.92)^{a}$ \\
\hline \multirow[t]{4}{*}{$\Delta \mathrm{a}^{*}$} & B-7 & $1.31(2.60)^{\mathrm{a}}$ & $0.58(2.63)^{\mathrm{a}}$ & $0.42(2.17)^{\mathrm{a}}$ & $-1.02(3.77)^{\mathrm{a}}$ & $1.68(3.02)^{\mathrm{a}}$ & $-0.55(2.01)^{a}$ \\
\hline & B-14 & $-0.45(1.97)^{a}$ & $0.60(0.83)^{a}$ & $0.10(3.59)^{a}$ & $-0.07(2.62)^{a}$ & $-0.08(1.39)^{a}$ & $-0.67(2.01)^{a}$ \\
\hline & B-21 & $1.23(2.16)^{a}$ & $1.36(2.67)^{\mathrm{a}}$ & $0.72(4.60)^{a}$ & $-1.36(3.70)^{a}$ & $1.92(3.32)^{a}$ & $-1.31(2.92)^{a}$ \\
\hline & B-28 & $-0.64(1.97)^{\mathrm{a}}$ & $-0.55(1.64)^{a}$ & $-0.99(3.60)^{\mathrm{a}}$ & $-0.34(2.18)^{\mathrm{a}}$ & $0.13(1.53)^{\mathrm{a}}$ & $-0.98(2.04)^{\mathrm{a}}$ \\
\hline \multirow[t]{4}{*}{$\Delta b^{*}$} & B-7 & $0.23(6.23)^{\mathrm{ab}}$ & $2.37(2.82)^{\mathrm{ab}}$ & $-1.31(2.38)^{a b}$ & $-1.28(5.20)^{\mathrm{ab}}$ & $1.90(2.55)^{\mathrm{ab}}$ & $-5.29(3.60)^{\mathrm{bc}}$ \\
\hline & B-14 & $-0.45(3.54)^{a b}$ & $1.61(2.92)^{\mathrm{ab}}$ & $0.47(6.51)^{\mathrm{ab}}$ & $-2.44(2.63)^{\mathrm{abc}}$ & $-0.74(2.28)^{a b}$ & $-3.29(5.89)^{\mathrm{bc}}$ \\
\hline & B-21 & $1.01(4.80)^{\mathrm{ab}}$ & $4.68(5.12)^{\mathrm{a}}$ & $-0.38(7.29)^{\mathrm{ab}}$ & $-4.45(6.67)^{\mathrm{bc}}$ & $1.61(3.84)^{\mathrm{ab}}$ & $-9.38(8.15)^{c}$ \\
\hline & B-28 & $0.50(3.05)^{\mathrm{ab}}$ & $0.26(2.93)^{\mathrm{ab}}$ & $1.00(7.21)^{\mathrm{ab}}$ & $-3.59(3.88)^{\mathrm{bc}}$ & $-0.69(2.39)^{a b}$ & $-5.16(5.73)^{\mathrm{bc}}$ \\
\hline \multirow[t]{4}{*}{$\Delta \mathrm{E}^{*}$} & $B-7$ & $9.08(5.46)^{\mathrm{ab}}$ & $7.17(4.91)^{b}$ & $9.04(6.81)^{a b}$ & $12.41(9.19)^{\mathrm{ab}}$ & $11.15(5.87)^{\mathrm{ab}}$ & $11.17(4.76)^{\mathrm{ab}}$ \\
\hline & B-14 & $9.62(8.04)^{\mathrm{ab}}$ & $8.18(5.70)^{\mathrm{ab}}$ & $15.38(10.07)^{\mathrm{ab}}$ & $10.10(4.11)^{\mathrm{ab}}$ & $12.09(5.41)^{\mathrm{ab}}$ & $11.06(5.79)^{\mathrm{ab}}$ \\
\hline & B-21 & $11.69(8.58)^{\mathrm{ab}}$ & $11.50(5.82)^{\mathrm{ab}}$ & $18.47(10.05)^{\mathrm{a}}$ & $15.46(3.44)^{\mathrm{ab}}$ & $12.95(5.84)^{\mathrm{ab}}$ & $15.49(6.18)^{\mathrm{ab}}$ \\
\hline & B-28 & $7.35(4.88)^{\mathrm{b}}$ & $5.12(3.25)^{\mathrm{b}}$ & $11.99(6.90)^{\mathrm{ab}}$ & $15.07(7.97)^{\mathrm{ab}}$ & $11.89(6.03)^{\mathrm{ab}}$ & $11.15(5.86)^{\mathrm{ab}}$ \\
\hline
\end{tabular}

* Different letters indicate statistically significant differences between groups within each $\Delta$

** $\mathrm{B}$ means Baseline - each value represents the $\Delta$ between the baseline and each mouth rinse application time

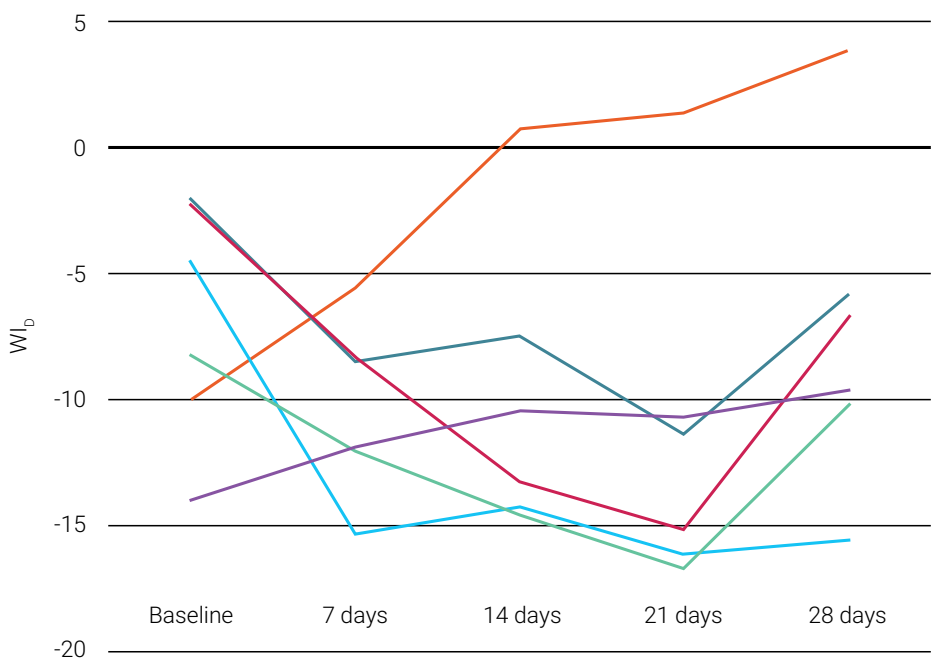

$-20$

Mouthrinse application time

$\begin{array}{ll}\text { Colgate Plax } & \text { Cepacol } \quad \text { Cisterine Cool Mint } \quad \text { Colgate Luminous White } \\ \text { Cepacol Whitening } & \text { Listerine Whitening Extreme }\end{array}$

Figure 3. $\mathrm{WI}_{\mathrm{D}}$ results of each mouth rinse over time 


\section{Discussion}

The limited evidence on the whitening effect of whitening mouth rinses associated with the extensive availability of these over-the-counter (OTC) products motivated this study. The influence of the type of mouth rinse on the overall color change $\left(\Delta E^{\star}\right)$ led to the rejection of the study hypothesis. Interestingly, a conventional (non-whitening) mouth rinse (Listerine Cool Mint) produced the highest $\Delta E^{\star}$, followed by whitening mouth rinses, which did not show statistical differences. On the other hand, $W I_{D}$ results showed a growing whitening effect over time from the hydrogen peroxide-containing mouth rinse Listerine Whitening Extreme (Figure 3), suggesting that the presence of this active ingredient is key for a mouth rinse that claims to whiten teeth to, in fact, provide this effect.

The whitening potential of whitening substances has been assessed, traditionally, by changes in CIEL*a*b* coordinates, expressed as $\Delta s\left(\Delta L^{*}, \Delta a^{*}, \Delta b^{*} \text { and } \Delta E^{*}\right)^{6-8}$. Still, most recently, the Whiteness Index for Dentistry $\left(\mathrm{WI}_{\mathrm{D}}\right)$ was developed aiding at determining more precisely the amount of whiteness produced by tooth whitening technologies ${ }^{12}$. According to Perez et al. ${ }^{12}$ (2016), the index has a very straightforward interpretation: the higher the positive index value, the whiter the tooth. Lower values, and even negative values are considered as poorly associated to whiteness ${ }^{12}$. In this study, all $\mathrm{WI}_{\mathrm{D}}$ values at baseline were negative. The only ascending tendency by immersion in mouth rinse over time was observed with the whitening mouth rinse containing hydrogen-peroxide, which only achieved positive values after 14 days of immersion.

As to $\mathrm{CIEL}{ }^{*} \mathrm{~b}^{\star}$ measures, the increase of lightness (increasing $L^{*}$ ) and the reduction of yellowness (decreasing $b^{*}$ ) are the main inducers of tooth whitening. The reduction of redness (decreasing $a^{*}$ ) affects whitening to a lesser extent ${ }^{8,13}$. Our results showed a reduction of $L^{*}$ (Figure 2 and Table 2 ), irrespective of the treatment group or application time, characterizing darkening of the tooth structure throughout the experiment. Figure 2 also shows a tendency of lightness recovery by some mouth rinses from day 21 to day 28 , although not fully restoring it. The presence of organic substances in the artificial saliva ${ }^{10}$ and the demineralizing effect of some low $\mathrm{pH}$ mouth rinses ${ }^{8}$ supposedly explain the lowering effect of lightness for in vitro settings.

A significant yellowness $\left(\Delta b^{*}\right)$ reduction was observed only for the $2.5 \%$ hydrogen peroxide Listerine Whitening Extreme mouth rinse. This mouth rinse also presented the lowest reduction of $L^{*}$, meaning a reduced darkening of the tooth, although not statistically significant. Finally, this mouth rinse, along with Colgate Luminous White, produced negative a* (again, not statistically significant), which means a reduced redness that tends to manifest after longer periods of whitening and to a lesser extent, representing improved tooth whitening ${ }^{8}$.

Some substances with whitening potential are common to whitening toothpastes and whitening mouth rinses. Phosphate-derived substances such as pyrophosphate, tripolyphosphate, and hexametaphosphate have prevented superficial stains ${ }^{14}$. Tetrapotassium pyrophosphate and tetrasodium pyrophosphate are present in Colgate Luminous White, which also tended to reduce $a^{*}$ and $b *$ values. Moreover, considering the general results, it seems that effective tooth whitening relates somewhat to the 
presence of hydrogen peroxide ${ }^{15}$. Among the three whitening mouth rinses, Listerine Whitening Extreme was the only one to contain hydrogen peroxide, to reduce $b$ * substantially (Figure 2) and to present a true whitening effect (Figure 3). Torres et al. ${ }^{6}$ (2013) observed a similar in vitro whitening effect for a mouth rinse containing $2 \%$ hydrogen peroxide and $10 \%$ carbamide peroxide gel. Considering that the $10 \%$ carbamide peroxide decomposes into $3.35 \%$ hydrogen peroxide ${ }^{3}$, the concentrations of the active whitening substance are similar.

Methodological disparities hindered the comparison of results of previous and the present in vitro study. They involve the type of tooth (human ${ }^{8}$ or bovine ${ }^{6,9,10}$ ), pre-staining $\left(\right.$ yes $^{6,9,15} / \mathrm{no}^{8,10}$ ), varying application protocols (number of immersions $-1 \mathrm{x}^{6}$, $2 x^{8,9}, 3 x^{10}$; and immersion times -1 minute ${ }^{6,8,9}$ or 2 minutes ${ }^{10}$ ), assessment times (30 days ${ }^{10}, 45$ days $^{8}$, up to 8 weeks ${ }^{9}$, and up to 12 weeks ${ }^{6,15}$ ), and color assessment procedures (standard digitized photographs ${ }^{8}$ or spectrophotometers ${ }^{6,9,10}$ ). Regarding the choices made in this study, bovine teeth have long been a reasonable alternative to mimic the characteristics of human teeth ${ }^{10}$. We did not pre-stain the teeth in this study, because artificial staining creates conditions to confirm a whitening effect in the presence of chromogenic molecules that may not be very intense in the teeth of a person demanding tooth whitening. Most mouth rinse manufacturers recommend a one-minute immersion. Although there is no specific recommendation on the frequency of daily applications, twice a day ${ }^{8,9}$ would be a clinically feasible frequency and it would improve the whitening effect as compared with a single daily application. The total application time of 28 days almost doubled some enhanced protocol times ${ }^{7,16}$ for tooth whitening with carbamide or hydrogen peroxide, which rarely takes one month in present days. The authors understand that this application time was sufficient to confirm any whitening effect from whitening mouth rinses. Finally, the digital spectrophotometer has long been reported as a reliable method for measuring the color change in whitening studies ${ }^{17}$ and, together with the $\mathrm{WI}_{\mathrm{D}}{ }^{12}$, it presents a good scenario of the whitening effect of whitening substances.

We assessed color weekly within a 28-day application period, generating four assessment intervals. The application time only affected $\Delta E^{*}$, with emphasis on the third week of whitening, which presented the highest $\Delta \mathrm{E}^{\star}$ values from the baseline (Table 2). Nonetheless, the yellowing reduction with Listerine Whitening Extreme was evident from day 7 (Figure 2). Chemically-induced peroxide tooth whitening products showed accumulation over time, enhancing the total contact time with the tooth structure ${ }^{4}$. Therefore, we may speculate that a longer experiment period would show clearer results from the hydrogen peroxide mouth rinse and that it could even affect the overall color change.

The color of the mouth rinses varied. Products from Cepacol had a yellow color, while those from Colgate were blue and those from Listerine presented a blueish/greenish color. Regardless of that, one believes that the product color may not have influenced the color results of teeth, since they remained in contact with the substances for a short period. Also, following the immersion protocols, the artificial saliva with some residual pigment was exchanged daily. One limitation of the study was that the $\mathrm{pH}$ of the mouth rinses was not assessed. 
Whitening mouth rinses are easy to acquire and represent low-cost alternatives for tooth whitening ${ }^{10}$. However, in vitro studies using different methods showed controversial results $6,8,10$, which are difficult to pool and compare. This study, for instance, used the conventional non-whitening counterparts as controls and revealed that some whitening mouth rinses do not achieve the expected whitening results. Dental researchers and dental clinicians could incorporate this information to design comprehensive independent clinical studies and advise potential consumers of whitening products. As for therapeutic technology, a sound decision-making process and the indication of whitening mouth rinses for tooth whitening depend on the scrutiny of proven effects resulting from randomized controlled trials attesting clinical efficacy and safety.

The overall color change produced by whitening mouth rinses in one month is not different from that produced by conventional mouth rinses. The whitening mouth rinse containing hydrogen peroxide reduced yellowing significantly during such application period and was the only whitening mouth rinse to present a true whitening effect.

\section{Acknowledgements}

This study was funded by FAPESC, grant no. 06/2017.

\section{References}

1. American Dental Association. Council on Scientific Affairs. Tooth whitening/bleaching: treatment considerations for dentists and their patients. Chicago: ADA. 2009 Sept [cited 2019 nov 25]. 12p. Available from: https://www.ada.org/ /media/ADA/About\%20the\%20ADA/Files/ada_house_of_ delegates_whitening_report.ashx.

2. Demarco FF, Meireles SS, Masotti AS. Over-the-counter whitening agents : Critical assessment of the OTC products for home-use bleaching. Braz Oral Res. 2009;23(Spec Iss 1):64-70. doi: 10.1590/S1806-83242009000500010.

3. Kwon SR, Wertz PW. Review of the mechanism of tooth whitening. J Esthet Restor Dent. 2015 Sep-Oct;27(5):240-57. doi: 10.1111/jerd.12152.

4. Serraglio CR, Zanella L, Dalla-Vecchia KB, Rodrigues-Junior SA. Efficacy and safety of overthe-counter whitening strips as compared to home-whitening with $10 \%$ carbamide peroxide gel-systematic review of RCTs and metanalysis. Clin Oral Investig. 2016 Jan;20(1):1-14. doi: 10.1007/s00784-015-1547-8.

5. Fasanaro TS. Bleaching Teeth: History, Chemicals, and Methods Used for Common Tooth Discolorations. J Esthet Dent. 1992 May-Jun;4(3):71-8.

6. Torres C, Perote L, Gutierrez N, Pucci C, Borges A. Efficacy of Mouth Rinses and Toothpaste on Tooth Whitening. Oper Dent. 2013 Jan-Feb;38(1):57-62. doi: 10.2341/11-360-L.

7. Meireles SS, Santos IS, Bona A Della, Demarco FF. A double-blind randomized clinical trial of two carbamide peroxide tooth bleaching agents: 2-year follow-up. J Dent. 2010 Dec;38(12):956-63. doi: 10.1016/j.jdent.2010.08.003.

8. Lima FG, Rotta TA, Penso S, Meireles SS, Demarco FF. In vitro evaluation of the whitening effect of mouth rinses containing hydrogen peroxide. Braz Oral Res. 2012 May-Jun;26(3):269-74.

9. Karadas M, Duymus ZY. In vitro evaluation of the efficacy of different over-the-counter products on tooth whitening. Braz Dent J. 2015 Jul-Aug;26(4):373-7. doi: 10.1590/0103-64402013×0111. 
10. Nahsan FPS, Reis MJO, Francisconi-dos-Rios LF, Leão L, Paranhos LR. Effectiveness of whitening mouthwashes on tooth color: An in vitro study. Gen Dent. 2018 Mar-Apr;66(2):e7-e10.

11. Santos PA. [Infuence of the light source on color stability of a compoiste resin. Effect of storage medium and storage times] [thesis]. Araraquara: São Paulo State University "Júlio de Mesquita Filho"; 2008. Portuguese.

12. Pérez MDM, Ghinea R, Rivas MJ, Yebra A, lonescu AM, Paravina RD, et al. Development of a customized whiteness index for dentistry based on CIELAB color space. Dent Mater. 2016 Mar;32(3):461-7. doi: 10.1016/j.dental.2015.12.008.

13. CIE. Commission Internationale de I'Eclairage. Recommendations on uniform color spaces-color difference equations, psyhometric color terms. Supplement No. 2 to CIE Publication No. 15 (E.-1.3. 1) 1971/(TC-1.3.). 1978.

14. Joiner A. Whitening toothpastes: A review of the literature. J Dent. 2010;38 Suppl 2:e17-24. doi: 10.1016/j.jdent.2010.05.017.

15. Oliveira J, Sarlo R, Bresciani E, Caneppele T. Whitening Efficacy of Whitening Mouth Rinses Used Alone or in Conjunction With Carbamide Peroxide Home Whitening. Oper Dent. 2017 May/Jun;42(3):319-26. doi: 10.2341/15-361-L.

16. Chemin K, Rezende M, Loguercio A, Reis A, Kossatz S. Effectiveness of and Dental Sensitivity to At-home Bleaching With 4\% and 10\% Hydrogen Peroxide: A Randomized, Triple-blind Clinical Trial. Oper Dent. 2018 May/Jun;43(3):232-40. doi: 10.2341/16-260-C.

17. Meireles SS, Demarco FF, Santos IS, Dumith SC, Bona A Della. Validation and Reliability of Visual Assessment with a Shade Guide for Tooth-Color Classification. Oper Dent. 2008 Mar-Apr;33(2):121-6. doi: 10.2341/07-71. 